\title{
GRAHAM STEELL
}

Graham Steell was one of the three original honorary members of the Cardiac Society. He was born in 1851, and died on January 10, 1942, in his ninety-first year. Happily to the very end, he retained to the full all his mental faculties. When, in recent years, the writer visited him in his London home, he often found him engrossed in a text-book of anatomy or medicine and always eager to discuss recent developments and to recall fascinating memories of his own teachers and contemporaries.

Graham Steell was the youngest son of Sir John Steell, sculptor to H.M. Queen Victoria in Scotland. The monument to Sir Walter Scott in Princes Street, which is familiar to all who have visited Edinburgh, was Sir John's work. Educated at the Edinburgh Academy, Steell's early ambition was to be a soldier; but he was persuaded by one of his brothers, for whom he had a great affection, to take up medicine. He qualified at Edinburgh in 1872, and, after spending the following winter studying in Berlin, became house-physician to George Balfour at the Edinburgh Royal Infirmary. It was doubtless this association with Balfour that was responsible for arousing Steell's interest in cardiology and for determining the field of medicine to which he devoted his life's work and in which he was destined to play such a distinguished part.

Except for a few months as resident medical officer to the Stirling Royal Infirmary, the next four years were spent in fever hospitals in Edinburgh, London, and Leeds, and his thesis for the degree of M.D., for which he was awarded a gold medal, was on scarlatina. Prior to coming to Manchester in 1878 he held the appointment of assistant to Professor (afterwards Sir Thomas) Fraser, in the department of materia medica and therapeutics at Edinburgh University.

In 1883, after serving for five years as resident medical officer, Steell was appointed assistant physician to the Manchester Royal Infirmary, to which institution and its patients he gave devoted service until his retirement from the active staff and from the university chair of clinical medicine at the age of sixty.

Amongst his testimonials for this post are many from distinguished men, including William Roberts, Thomas Fraser, William Broadbent, George Balfour, Daniel Leech, Lauder Brunton, Clifford Allbutt, James Ross, F. A. Mahomed, and William Turner. In his testimonial Mahomed wrote, " His modest retiring and courteous disposition must gain the highest esteem of all who have the privilege of knowing him well." The present writer, who had that privilege thirty years later, can find no words that would more aptly describe his character: in fact, his modesty and courtesy would have been almost embarrassing to his younger friends had they not realized the truehearted kindness that lay below. 


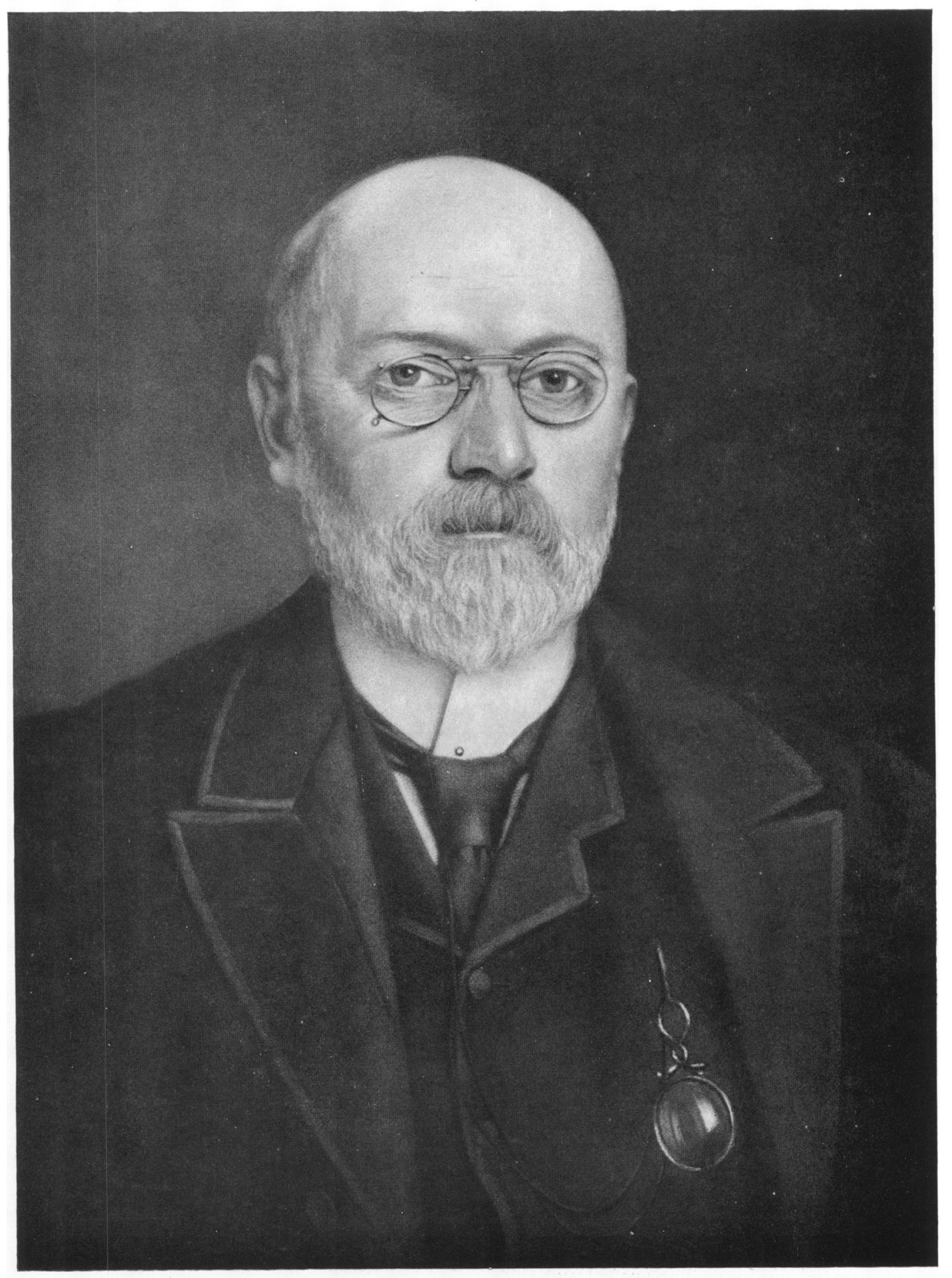

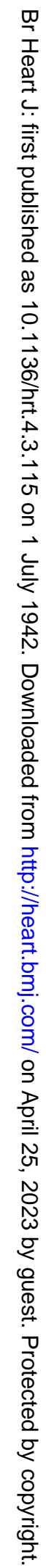


In view of his extensive experience in fevers, it is not surprising that many of his early papers were devoted to this subject, but from 1886 onwards, with the exception of occasional excursions into the adjacent pulmonary field, all but two of his publications dealt with cardiology.

His text-book on Diseases of the Heart, published in 1906, never achieved the popularity it deserved. In a letter of thanks for a presentation copy, Mackenzie wrote, "Many congratulations on your excellent handbook, and many thanks for the copy. I have been eagerly devouring it, and I have no hesitation in saying it is by far the best book on the heart on the market. Your remarks are so pungent and pithy that it is a delight to read."

This book was no mere compilation of current doctrine: the views expressed were based on the author's own clinical and pathological observations, the full significance of some of which was not apparent until many years later. For example, in reference to ædema he wrote:

"Capricious distribution of dropsy is specially apt to occur in cases of the cardiac muscle-failure of beer-drinkers and of the disease known as beri-beri, of both of which diseases, it is curious to note, peripheral neuritis is a clinical feature. . . . Curious special localizations of œdema met with, in cases of the kind, have been the scrotum, and together the upper trunk, upper extremities, and scalp and neck, so that the odema simulates that resulting from mediastinal tumour."

We now know that this type of heart failure, and the peripheral neuritis with which it is often associated, are due to vitamin $B_{1}$ deficiency: hence the relation that puzzled Steell, between beri-beri and chronic alcoholism.

Another problem that puzzled him was the occasional association of transient pericardial friction with angina pectoris. His paper recording these observations was published many years before the clinical syndrome of coronary thrombosis was recognized in this country.

The murmur of pulmonary incompetence that bears Steell's name was first described by him in a paper read to the Manchester Medical Society and afterwards published in the Medical Chronicle in 1888. He wrote as follows:

"I wish to plead for the admission among the recognized auscultatory signs of disease of a murmur due to pulmonary regurgitation, such regurgitation occurring independently of disease or deformity of the valves, and as the result of long-continued excess of blood pressure in the pulmonary artery.

"In cases of mitral obstruction there is occasionally heard over the pulmonary area (the sternal extremity of the third left costal cartilage), and below this region for the distance of an inch or two along the left border of the sternum, and rarely over the lowest part of the bone itself, a soft blowing diastolic murmur immediately following, or, more exactly, running off from the accentuated second sound, while the usual indications of aortic regurgitation, afforded by the pulse, etc., are absent. The maximum intensity of the murmur may be regarded as situated at the sternal end of the third and fourth intercostal spaces. When the second sound is reduplicated, the murmur proceeds from its latter part. That such a 
murmur as I have described does exist, there can, I think, be no doubt. . . . The murmur of high pressure in the pulmonary artery is not peculiar to mitral stenosis, although it is most commonly met with as a consequence of this lesion. Any long-continued obstruction in the pulmonary circulation may produce it. The pulmonary valves, like the aortic, do not readily become incompetent, apart from structural changes. Probably no amount of blood pressure in the pulmonary artery will render them so suddenly, as, at least theoretically, the mitral valves may be rendered incompetent. Changes in the vessel, with widening of its channel, and, eventually, of its orifice, long precede the occurrence of incompetence of its valves. The pulmonary murmur of high pressure is probably never persistent at first, and one of its most remarkable features is, as a rule, its variableness in intensity. On some days it will be distinctly heard, on others it will be indistinct, or even inaudible; while extreme accentuation of the pulmonary second sound is always present, the closure of the pulmonary semilunar valves being generally perceptible to the hand placed over the pulmonary area, as a sharp thud. This non-persistence of the murmur, in the earlier stages, at any rate, is only what the study of dilatation of the aorta and the consequent regurgitation would lead us to expect. Indeed, so common is a soft blowing murmur, after an accentuated aortic second sound, that extreme accentuation should make us listen, with special care, for a murmur, and even though it be absent on the first occasion the search should not be abandoned. My belief is, that when the aortic second sound is extremely accentuated, regurgitation, to some extent, will probably occur sooner or later. Its supervention in aneurysm of the first part of the arch of the aorta is a familiar fact. Post-mortem, enlargement of the left ventricle, in these cases, may be a better indication of regurgitation having occurred during life than the usual test of filling the cut aorta with water, a proceeding which cannot imitate the action of the forcible blood currents in the living body. An accentuated second sound is no way incompatible with a certain amount of incompetence of the semilunar valves; on the contrary, an accentuated second sound, associated with a regurgitant murmur, is clinically common."

In addition to his text-book and numerous original papers in scientific journals, Steell published three small monographs devoted to the Physical Signs of Cardiac Disease (1881), the Physical Signs of Thoracic Disease (1900), and The Use of the Sphygmograph in Clinical Medicine (1889). The sphygmograph had always fascinated him, and he made a practice of taking pulse tracings from all his cardiac patients. From references to this subject in their correspondence it is evident that these records were of great interest to Mackenzie who, when in practice in Burnley, used often to go round Steell's wards in the Manchester Royal Infirmary. Two men outwardly more different it would be hard to imagine, but they were close friends and had the highest regard for each other's work.

Although keenly interested in auscultation (he always used a monaural stethoscope made of box-wood with a bell-shaped earpiece), Steell laid great 
stress on disease of the heart muscle rather than of the valves as the factor of primary clinical importance. His " master," Balfour, had coined the term "curable mitral regurgitation" to distinguish the mitral incompetence associated with conditions such as chlorosis from the "mitral disease" due to a damaged valve. This conception greatly appealed to Steell, and in the preface to his book he wrote:

"No mitral valves can be competent if they fail to receive that assistance from the heart muscle that they were designed to receive in the performance of their function."

In 1911 Steell delivered the Bradshaw lecture at the Royal College of Physicians. His subject "Intra-thoracic Tumours and Aneurysms in their Clinical Aspect" was one that had interested him deeply for many years and afforded ample scope for his special talents. He was at his best as a bedside teacher when demonstrating the physical signs of intrathoracic disease and considering their interpretation.

Steell was a lover of animals, and a staunch advocate of physical exercise: himself a boxer in his youth and later a keen horseman, he often recommended riding as the best form of exercise for those of his cardiac patients whose disability was slight. He was the last Manchester consultant to keep a brougham and pair. In a letter to the writer in 1931, he said, "For the last ten years and more the importance of exercise in the treatment of heart troubles has been more and more borne in upon me and, in my own case, I have more and more made application of it. . . . The beginning of my heart troubles was in 1898: an extreme irregularity and frequency of the pulse, which went on continuously for weeks. I have normally regarded this as auricular fibrillation, but your paper raises doubts in my mind. Your phrase 'showers of extrasystoles' at any rate appeals to me in a way impossible to anyone who has not gone through experience of such a condition." In addition to heart trouble he had more than his fair share of the diseases he knew so well. In his young days he contracted both typhoid and typhus, and in 1888 he was off work for some months, tubercle bacilli having been found in his sputum.

After the last war Steell retired from practice and went to live with his son, who was for a time in practice in Derbyshire and who later became a medical officer of the Ministry of Health, first in Newcastle and subsequently in London. The writer well remembers the concern of his son, when one day he discovered the old man embarking on an original research on the colour sense of young bullocks by waving a red handkerchief at them in the field adjacent to his house!

He married in 1886 Agnes Dunlop McKie, who was Lady Superintendent of nurses of the Manchester Royal Infirmary. She died in 1910. They had one son, to whom the writer is indebted for the great privilege of having enjoyed the friendship of Graham Steell.

Crighton Bramwell. 